\title{
Non-cardiac surgery in congenital heart disease-associated pulmonary arterial hypertension: risk recognition and management
}

\author{
Andrew Constantine ${ }^{1 *}$ (D) and Paul Clift $^{2}$
}

\begin{abstract}
Background: Current guidelines for the peri-operative assessment and management are not sufficient to allow effective risk assessment and management of the patient with pulmonary arterial hypertension associated with congenital heart disease. Well-established risk stratification tools are not validated in this group. Additional, diseasespecific risks require individualised, specialist, multidisciplinary management.

Case presentation: We present an illustrative clinical case of patients with pulmonary arterial hypertension associated with congenital heart disease undergoing non-cardiac surgery. The case follows a 66-year-old male with pulmonary hypertension associated with an atrial septal defect underwent an elective hernia repair.

Conclusions: We discuss useful management strategies for minimising risk during the peri- and post-operative periods in this population.

Keywords: Congenital heart disease, Pulmonary arterial hypertension, Risk assessment, Non-cardiac surgery, Perioperative risk
\end{abstract}

\section{Background}

Individualised pre-assessment is the current standard of care prior to elective surgery, and specific guidelines exist for the peri-operative assessment and management of patients with acquired heart disease [1-4]. These guidelines are not sufficient to allow effective risk assessment and management of the patient with pulmonary arterial hypertension associated with congenital heart disease (PAH-CHD). Such patients are usually younger and are at lower risk of atherosclerotic coronary artery disease, but are at greater risk of arrhythmias, heart failure, paradoxical embolism or defect-specific

\footnotetext{
* Correspondence: andrew.constantine@nhs.net

'Adult Congenital Heart Centre and Centre for Pulmonary Hypertension, Royal Brompton Hospital, Sydney Street, London SW3 6NP, UK

Full list of author information is available at the end of the article
}

complications [5, 6]. Procedure-specific estimates of cardiovascular risk employed in guidelines may, therefore, underestimate the risk in PAH-CHD patients.

Objective measures of exercise capacity are wellestablished tools for risk stratification in patients with acquired heart disease. An exercise capacity of less than 4 metabolic equivalents (METS), equating to an inability to climb two flights of stairs, is associated with a greater incidence of post-operative cardiac events [7]. The average peak $\mathrm{VO}_{2}$ of a patient with Eisenmenger syndrome (ES) is $11.5 \mathrm{~mL} / \mathrm{kg} / \mathrm{min}$, which equates to less than 4 METS [8], and indicates a higher risk. Subjective measures of exercise tolerance, such as the New York Heart Association (NYHA) functional classification, may be misleading and difficult to interpret in the PAH-CHD patients who have a tendency to underplay their 
symptoms, making NYHA functional class a poor surrogate of exercise capacity in this population [9]. Individuals with $\mathrm{PAH}-\mathrm{CHD}$ have additional disease-specific risks, which require meticulous, directed management depending on the mechanism of pulmonary hypertension, the degree of cyanosis and the presence of systemic ventricular dysfunction or severe obstructive valvular lesions. Hence, while it is accepted that general anaesthesia and sedation carry significant risks in all PAH-CHD patients, it is difficult to stratify patients within this group into higher-and lower-risk subjects (increased versus prohibitive risk). Therefore, accurate pre-operative risk evaluation in PAHCHD should take into account the risk inherent to the specific procedure, traditional cardiac risk factors and the CHD-specific risks [6].

We present a clinical case which illustrates some of the specific risks encountered in $\mathrm{PAH}-\mathrm{CHD}$ patients undergoing non-cardiac surgery.

\section{Case presentation}

A 66-year-old man attended the outpatient adult congenital heart disease (ACHD) clinic. He had a history of a large secundum atrial septal defect (ASD) and had presented 15 years earlier with paroxysmal atrial fibrillation. On presentation, the echocardiogram had shown evidence of pulmonary hypertension (PH), with an estimated right ventricular systolic pressure (RVSP) of $70 \mathrm{mmHg}$. After a detailed work-up, he was felt to be operable, but the patient declined ASD repair at this point.

He then developed a large irreducible inguinal hernia, which was impacting on his quality of life. He was reviewed by the general surgeons at his local district general hospital. The surgical team planned for operative management, and he was reviewed by an anaesthetist at pre-assessment. In clinic, he was in functional class II, on an ACE inhibitor for mild systemic hypertension and was a current smoker. He was not taking any anticoagulation or anti-platelet therapy. Examination revealed an oxygen saturation level of $93 \%$ on room air, a right ventricular heave with a fixed, split second heart sound and no pedal oedema. His 12-lead ECG showed atrial fibrillation (Fig. 1). Following discussion with the surgical consultant, the patient's PAH-CHD team were contacted for advice on surgical risk and optimisation.

A full pre-operative assessment was undertaken at his PAH-CHD centre. Repeat echocardiography (Fig. 2a \& b) showed that the RVSP was unchanged. He had moderate mitral regurgitation and moderate-severe tricuspid regurgitation with significant RV systolic impairment (tricuspid annular plane systolic excursion $8 \mathrm{~mm}, \mathrm{RV} \mathrm{S}$ $7 \mathrm{~cm} / \mathrm{s})$. On cardiopulmonary exercise testing he managed $5 \mathrm{~min} 38 \mathrm{~s}$ on a cycle ergometer, achieving a

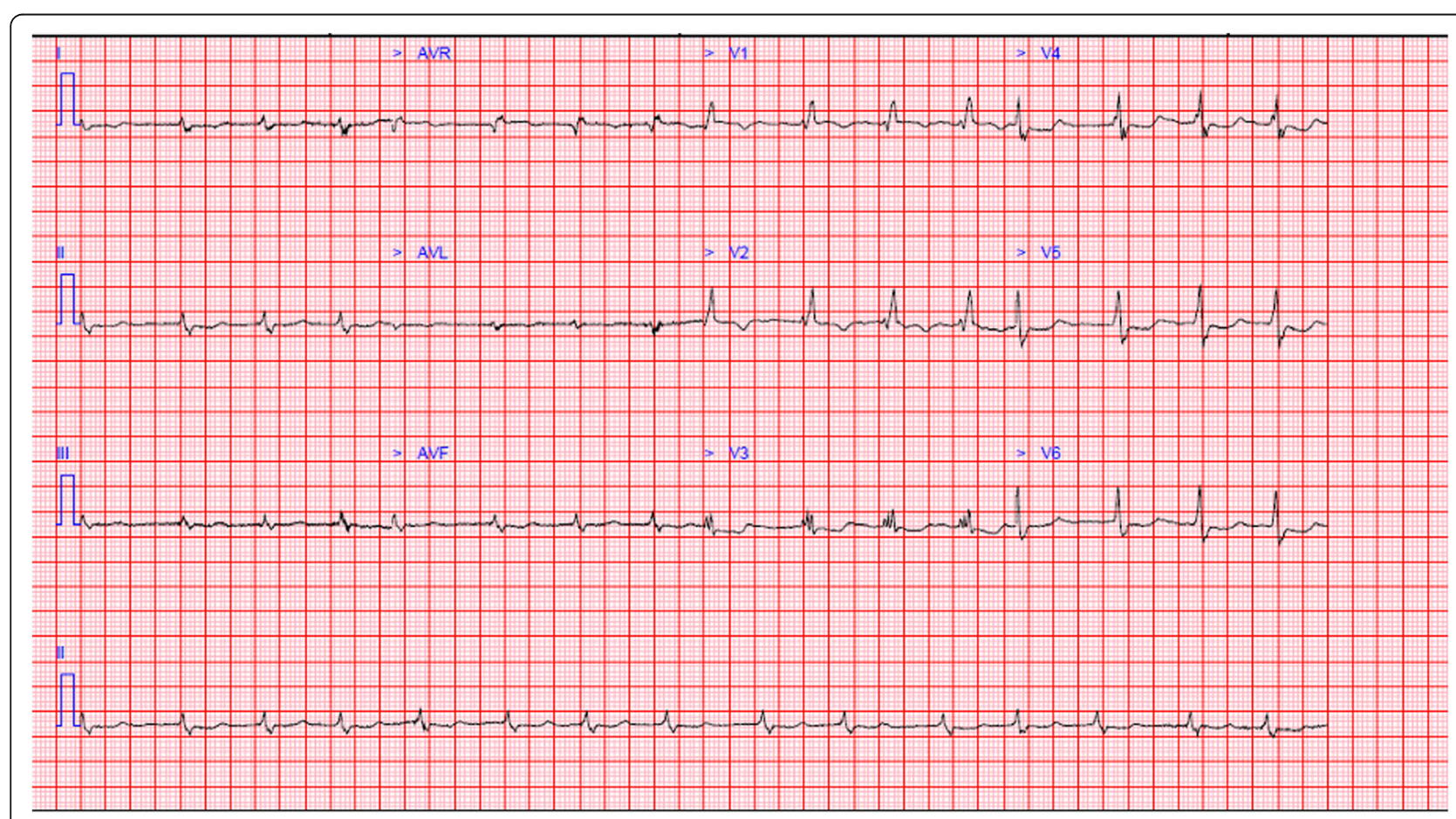

Fig. 1 12-lead ECG showing atrial fibrillation at a rate of 90 beats per minute. There is a mean QRS axis of $60^{\circ}$, a right bundle branch block pattern, and a lack of R-wave progression in the chest leads, in keeping with right ventricular 'dominance'. Widespread ST-T wave changes 

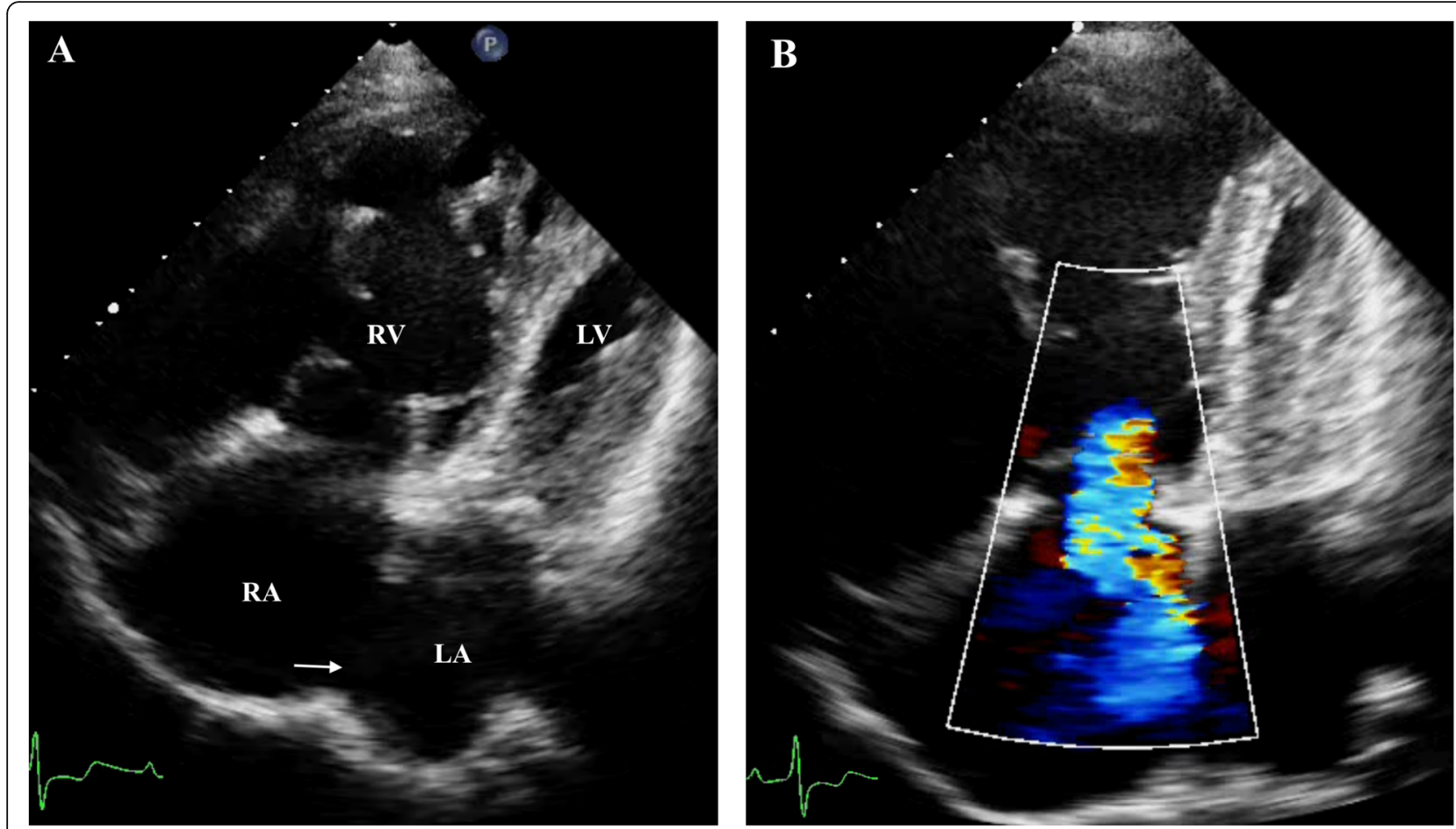

Fig. 2 Trans-thoracic echocardiography, illustrating (a) a large ASD (arrow) with dilated right atrium (RA) and ventricle (RV) and small left atrium $(\mathrm{LA})$ and ventricle (LV), and (b) a broad jet of moderate-severe tricuspid regurgitation

respiratory exchange ratio (RER) of 1.12. Peak $\mathrm{VO}_{2}$ was $15 \mathrm{~mL} / \mathrm{kg} / \mathrm{min}$ (60\% predicted) with an anaerobic threshold of $10 \mathrm{~mL} / \mathrm{kg} / \mathrm{min}$. Right heart catheterisation (RHC), under local anaesthesia on room air showed (compared to results from a RHC undertaken in 2001): mean pulmonary arterial pressure $58 \mathrm{mmHg}$ (previous $44 \mathrm{mmHg}$ ), pulmonary capillary wedge pressure $18 \mathrm{mmHg}$ (previous $12 \mathrm{mmHg}$ ), trans-pulmonary gradient $40 \mathrm{mmHg}$ (previous $32 \mathrm{mmHg}$ ), pulmonary blood flow $4.3 \mathrm{~L} / \mathrm{min}$ (previous $8 \mathrm{~L} / \mathrm{min}$ ), mixed systemic venous saturation $61 \%$ (previous 78\%), pulmonary arterial saturations 68\% (previous $88 \%$ ), systemic saturation $93 \%$ (98\%). On the latest catheter, the pulmonary vascular resistance (PVR) had risen from 4 Wood Units (WU) to almost 9.2 WU, with a drop in pulmonary blood flow and bidirectional shunting with mildly reduced systemic saturations.

These results signified markedly impaired exercise capacity and the catheter data were suggestive of combined pre- and post-capillary pulmonary hypertension, with a significant precapillary component, 'out of proportion' with the severity of left heart disease (diastolic dysfunction of the left ventricle and moderate mitral regurgitation). A joint multi-disciplinary team meeting was held, which was attended by the $\mathrm{PH}$ and CHD teams, a senior cardiac anaesthetist and a general surgeon and imaging specialists. Various options for anaesthetic management were considered, including performing the hernia repair under local, epidural, spinal or general anaesthesia. Non-surgical options were also discussed given the high-risks status of the patient. The risk of a pulmonary hypertensive crisis and RV dysfunction were stressed, as well as the potential for haemodynamic instability and the need for effective pain management. The congenital cardiac anaesthetist considered the possibility of worsening of the PVR and right-to-left shunting whilst under general anaesthesia and intermittent positive pressure ventilation. The length of the operation and the degree of fluid shift were estimated and considered with the aid of the surgical team. Limiting the size of the incision to limit post-operative pain and the use of epidural anaesthesia versus patient-controlled analgesia were deliberated. The consensus was that the operation should be undertaken at the specialist centre. Due to the evidence of significant RV impairment in the context of severe pulmonary hypertension and the high perceived risk of a pulmonary hypertensive crisis, the experienced congenital cardiac anaesthetist opted for giving a general anaesthetic with close monitoring of RV function.

The patient decided to proceed with surgery and underwent general anaesthesia with extra precautions employed in a high-risk pulmonary hypertension case: The patient was allowed to drink free fluids until $1 \mathrm{~h}$ before anaesthesia, peripheral venous cannulation was performed with the patient awake and, once anaesthetised, central venous and peripheral arterial catheters were 
placed. Trans-oesophageal echocardiography was performed and inhaled nitric oxide was used early during surgery. Post-operatively, the patient was taken to the Intensive Care Unit asleep and was woken up gradually. He was discharged from hospital 3 days later.

\section{Discussion and conclusions}

PAH-CHD patients undergoing essential cardiac and non-cardiac surgery should be managed in a regional congenital heart disease (CHD) and PH centre with integrated care led by a cardiologist specialising in paediatric or adult $\mathrm{CHD}$ and $\mathrm{PH}$. A thorough, multidisciplinary pre-assessment and meticulous perioperative management by an experienced cardiac anaesthetist should be presumed to be the standard of care, particularly in the absence of large prospective trials in this area [10-12]. The ES heart is highly preload dependent; fluid shifts can lead to a significant fall in cardiac output. Decreases in systemic vascular resistance (SVR) can enhance rightto-left shunt, worsening cyanosis and precipitating cardiovascular collapse. Increases in SVR can lead to a decrease in ventricular function, especially if associated with a sudden rise in PVR (PH crisis) [13]. This precarious physiology requires meticulous peri-operative management, with maintenance of SVR and ventricular contractility and avoidance of excessive blood loss and intravascular volume depletion. In cases of primary inguinal hernia repair, intraoperative fluid shifts are limited with experienced anaesthetic guidance, and preoperative dehydration was avoided by allowing the patient to drink clear fluids until $1 \mathrm{~h}$ prior to anaesthesia.

The intraoperative management is specific to the procedure being performed, but certain general principles should be followed. The preferred form of induction of anaesthesia is intravenous with systemic vasopressor agents available to maintain SVR [14]. In the past, there has been a perceived risk of inhalational anaesthetic agents having a less predictable effect on SVR, but many experienced anaesthetists use them successfully in combination with intravenous agents, reinforcing the importance of appropriate training and expertise of the anaesthetic team looking after these highly complex patients $[11,15,16]$. As with all cyanotic cardiac patients, the right-to-left shunt carries a risk of systemic paradoxical embolization, and all intravenous injections or infusions should be given through filtered or monitored lines.

Arterial monitoring is useful, as is intraoperative transoesophageal echocardiography (TOE) monitoring. Pulmonary artery catheters are generally avoided, however, due to the potential for complications [17], such as crossing the shunt lesion or pulmonary artery rupture [18]. If blood loss is anticipated, early cross-match is advised, as antibodies are common. When 'correcting' a low haemoglobin, normal reference values of less than $150 \mathrm{~g} / \mathrm{L}$ should not be used, as patients with ES require a higher haemoglobin concentration than healthy adults, to compensate for the chronic hypoxaemia (secondary erythrocytosis) [19].

Finally, the patient, family and the treating teams should be prepared for an Intensive Care Unit stay and prolonged post-operative ventilation. The mortality rate of non-cardiac surgery in ES is reported around 3\% in expert hands, even though the risks are likely to vary greatly according to the nature, complexity and urgency of the procedure (e.g. emergency cardiac surgery versus routine abdominal surgery versus dental procedures) [14].

Even when emergency surgery is required in a local hospital, telephone advice may be lifesaving for the patient as there are several disease-specific risks and precautions, which need to be considered and appropriately managed to increase the likelihood of a good outcome.

\section{Abbreviations \\ ACE: Angiotensin-converting enzyme; ACHD: Adult congenital heart disease; ASD: Atrial septal defect; CHD: Congenital heart disease; \\ ECG: Electrocardiogram; ES: Eisenmenger syndrome; METS: Metabolic equivalents; NYHA: New York Heart Association; PAH-CHD: Pulmonary arterial hypertension associated with congenital heart disease; PH: Pulmonary hypertension; PVR: Pulmonary vascular resistance; RER: Respiratory exchange ratio; RHC: Right heart catheterisation; RV S': Tissue Doppler systolic signal velocity of lateral tricuspid annulus; RVSP: Right ventricular systolic pressure; SVR: Systemic vascular resistance; TAPSE: Tricuspid annular plane systolic excursion; TOE: Trans-oesophageal echocardiography; Peak $\mathrm{VO}_{2}$ : Peak oxygen uptake; WU: Wood Unit}

\section{Acknowledgements}

We wish to acknowledge Professor Konstantinos Dimopoulos, Professor Robert Tulloh and Dr. Robin Condliffe, who, as members of the CHAMPION steering committee, reviewed the manuscript.

\section{About this supplement}

This article has been published as part of Journal of Congenital Cardiology Volume 4 Supplement 1 2020: Unmet needs in Pulmonary Hypertension associated with Adult Congenital Heart Disease (ACHD-PH). The full contents of the supplement are available at https://jcongenitalcardiology. biomedcentral.com/articles/supplements/volume-4-supplement-1.

\section{Authors' contributions}

Both authors drafted sections of the paper and approved the final paper for submission.

\section{Funding}

Medical writing support was provided by nspm Itd, Meggen, Switzerland. The manuscript was funded by a Medical and Educational Goods and Services (MEGS) grant and Actelion Pharmaceuticals UK Limited (who had no influence on manuscript writing).

Availability of data and materials Not applicable.

Ethics approval and consent to participate No ethics approval was required. 


\section{Consent for publication}

Written consent was obtained for the use of anonymised images. The case histories, including the demographic characteristics of patients, were altered in order to protect the patients' identities.

\section{Competing interests}

The CHAMPION group has received an unrestricted educational grant from Actelion Pharmaceuticals. PC has received honoraria from Actelion and Bayer. AC has received an educational grant from Actelion UK. There are no competing interests that have influenced the contents of the article.

\section{Author details}

${ }^{1}$ Adult Congenital Heart Centre and Centre for Pulmonary Hypertension, Royal Brompton Hospital, Sydney Street, London SW3 6NP, UK. ${ }^{2}$ Department of Cardiology, Queen Elizabeth Hospital, Birmingham, UK.

Received: 12 November 2020 Accepted: 12 November 2020

Published: 16 December 2020

\section{References}

1. Kristensen SD, Knuuti J, Saraste A, Anker S, Bøtker HE, De Hert S, Ford I, Gonzalez-Juanatey JR, Hoeft A, Huber K, lung B, Kjeldsen KP, Longrois D, Luscher TF, Pierard L, Pocock S, Price S, Roffi M, Sirnes PA, Sousa-Uva M, Voudris V, Funck-Brentano C. 2014 ESC/ESAGuidelines on non-cardiac surgery: cardiovascular assessment andmanagement. Eur Heart J. 2014;35: 2383-431. https://doi.org/10.1093/eurhearti/ehu282.

2. Fleisher LA, Fleischmann KE, Auerbach AD, Barnason SA, Beckman JA, Bozkurt B, Davila-roman VG, Gerhard-herman MD, Holly TA, Kane GC, Marine JE, Nelson MT, Spencer CC, Thompson A, Ting HH, Uretsky BF, Wijeysundera DN. ACC / AHA clinical practice guideline 2014 ACC / AHA guideline on perioperative cardiovascular evaluation and management of patients undergoing noncardiac surgery. Circulation. 2014;130:e278-333. https://doi. org/10.1161/CIR.0000000000000106

3. National Institute for Health and Care Excellence (NICE), Preoperative tests (update). Routine preoperative tests for elective surgery. Clinical guideline NG45., (2016). https://www.nice.org.uk/guidance/ng45. Accessed 19 May 2020.

4. The Association of Anaesthetists of Great Britain and Ireland. Pre-operative assessment and patient preparation - the role of the anaesthetist: The Association of Anaesthetists of Great Britain and Ireland; 2010. https://doi. org/10.21466/g.PAAPP-T.2010.

5. Maxwell BG, Wong JK, Kin C, Lobato RL. Perioperative outcomes of major non-cardiac surgery in adults with congenital heart disease. Anesthesiology. 2018:119:762-9.

6. Lui G, Saidi A, Burchill L, Deen J, Earing M, Gewitz M, Ginns J, Kay J, Kim YY, Kovacs AH, Krieger EV, Wu FM, Yoo S-J. Diagnosis and management of noncardiac complications in adults with congenital heart disease: a scientific statement from the American Heart Association. Circulation. 2017;136:e1-46. https://doi.org/10.1161/CIR.0000000000000535.

7. Biccard BM. Relationship between the inability to climb two flights of stairs and outcome after major non-cardiac surgery : implications for the preoperative assessment of functional capacity. Anaesthesia. 2005;60:588-93.

8. Diller G, Dimopoulos K, Okonko D, Li W, Sonya V, Broberg CS, Johansson B, Bouzas B, Mullen MJ, Francis DP, Gatzoulis MA. Exercise intolerance in adult congenital heart disease. Circulation. 2005;112:828-35. https://doi.org/10. 1161/CIRCULATIONAHA. 104.529800.

9. Bredy C, Ministeri M, Kempny A, Alonso-gonzalez R, Swan L, Uebing A, Diller G, Gatzoulis MA, Dimopoulos K. New York Heart Association ( NYHA) classification in adults with congenital heart disease: relation to objective measures of exercise and outcome. Eur Heart J. 2017:1-8. https://doi.org/10. 1093/ehjqcco/qcx031.

10. Niwa K, Perloff JK, Kaplan S, Child JS, Miner PD. Eisenmenger syndrome in adults: ventricular septal defect, truncus arteriosus, univentricular heart. J Am Coll Cardiol. 1999:34:223-32.

11. Ammash NM, Connolly HM, Abel MD, Warnes CA. Noncardiac surgery in Eisenmenger syndrome. J Am Coll Cardiol. 1999;33:222-7.

12. Raines $D E$, Liberthson RR, Murray R. Anesthetic management and outcome following noncardiac surgery in nonparturients with Eisenmenger's physiology. J Clin Anesth. 1996;8:341-7.

13. Lovell AT. Anaesthetic implications of grown-up congenital heart disease. $\mathrm{Br}$ J Anaesth. 2004;93:129-39. https://doi.org/10.1093/bja/aeh172.
14. Bennett JM, Ehrenfeld JM, Markham L, Eagle S. Anesthetic management and outcomes for patients with pulmonary hypertension and intracardiac shunts and Eisenmenger syndrome : a review of institutional experience. I Clin Anesth. 2014;26:286-93. https://doi.org/10.1016/j.jclinane.2013.11.022.

15. Foster JMG, Jones RM. The anaesthetic management of Eisenmenger syndrome. Ann R Coll Surg Engl. 1984;66:353-5.

16. Lumley J, Whitwam JG, Morgan M. General anesthesia in the presence of Eisenmenger's syndrome. Anesth Analg. 1977;56:543-7.

17. Devitt JH, Noble WH, Byrick RJ. A Swan-Ganz catheter related complication in a patient with Eisenmenger's syndrome. Anesthesiology. 1982;57:335-7.

18. Barash PG, Nardi D, Hammond G, Walker-Smith G, Capuano D, Laks H, Kopriva CJ, Baue AE, Geha AS. Catheter-induced pulmonary artery perforation. Mechanisms, management, and modifications. J Thorac Cardiovasc Surg. 1981;82:5-12.

19. Diller G, Dimopoulos K, Broberg CS, Kaya MG, Naghotra US, Uebing A, Harries C, Goktekin O, Gibbs JSR, Gatzoulis MA. Presentation, survival prospects, and predictors of death in Eisenmenger syndrome: a combined retrospective and case-control study. Eur Heart J. 2006;27:1737-42. https:// doi.org/10.1093/eurheartj/ehl116.

\section{Publisher's Note}

Springer Nature remains neutral with regard to jurisdictional claims in published maps and institutional affiliations.

Ready to submit your research? Choose BMC and benefit from:

- fast, convenient online submission

- thorough peer review by experienced researchers in your field

- rapid publication on acceptance

- support for research data, including large and complex data types

- gold Open Access which fosters wider collaboration and increased citations

- maximum visibility for your research: over $100 \mathrm{M}$ website views per year

At BMC, research is always in progress.

Learn more biomedcentral.com/submissions 